\title{
Power Processing Circuits for Vibration-Based Energy Harvesters
}

\author{
R. D'hulst, and J. Driesen \\ K.U.Leuven, ESAT-ELECTA \\ Kasteelpark Arenberg 10, 3001 Leuven, Belgium
}

\begin{abstract}
In this paper the behavior of a piezo-electric vibration-driven energy harvester is assessed with different power processing circuits. Firstly, a general model for vibration-driven harvesters is described. Using this model, an optimal linear resistive load for the harvester can be analytically calculated. As the vibration-based harvester provides varying $\mathrm{AC}$ power, while electronic loads need a stable DC power supply, it is useful to analyze the harvester behavior when connected to a non-linear AC-DC rectifier. Using the same general model, an optimal DC voltage load can be calculated for every frequency. The difference between the optimal output power flow from the harvester to both load circuits depends on the coupling coefficient of the harvester device. To validate previous conclusions, two power processing circuits are designed and built, the first emulating a resistive input impedance and the second with a constant input voltage. A piezo-electric bimorph is taken as energy harvesting device. A buck-boost DC-DC converter without input filter capacitor, operating in discontinuous conduction mode, is shown to have a resistive input impedance. A buck converter with input filter capacitor is used to evaluate the rectifier load-case. Simulations and experimental validation show that the efficiency of the overall system, harvester device with power processing circuit, increases if the power processing circuit has a fixed DC-voltage as input.
\end{abstract}

\section{INTRODUCTION}

The current advances in performance and functionality of micro- and nano-systems have stimulated the development of intelligent networks of autonomous systems. The demand for a small, mobile and reliable energy supply for each autonomous network node has led to the development of a new type of generators, as the use of conventional electrochemical batteries is not always an option because of their limited lifespan, the need for replacement, and the volume-dependency of the amount of stored energy. Motion energy or vibrations are an attractive source for powering miniature energy harvesting generators [1]. Vibration energy can be converted into electrical energy through piezo-electric, electromagnetic and electrostatic devices, this work focuses on piezo-electric devices. The output power of such devices, made using MEMS techniques, is limited, ranging from milliwatts down to only a few microwatts.

\section{HARVESTER MODEL}

Energy harvesters of the inertial type are considered, the motion of the vibration source is coupled to the generator by means of the inertia of a seismic mass. This mass $m$ is modeled as being suspended by a spring with spring constant $k$, while its motion is damped by a parasitic damping $d$ due to

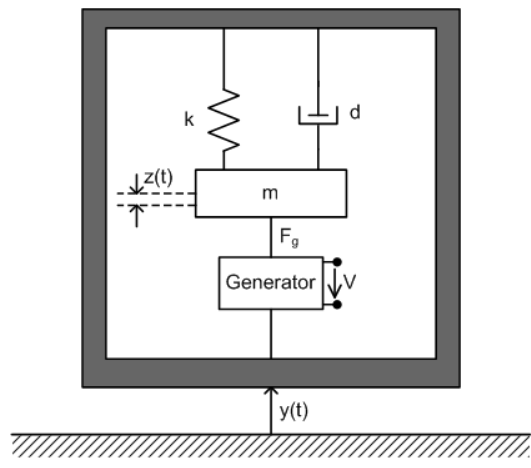

Fig. 1. General mass-spring-damper model of vibration-based harvester.

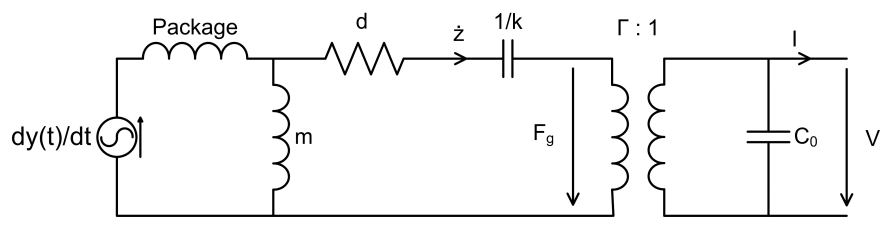

Fig. 2. Electrical circuit equivalent of vibration-based harvester model

friction and air. The mass is also damped by the generator, e.g. a piezoelectric transducer, exerting a force $F_{g}$, see Fig. 1 . The displacement of the mass is $z(t)$ and the displacement of the package is $y(t), I$ and $V$ are the outgoing current and voltage. This system is governed by following differential equation:

$$
m \ddot{y}=m \ddot{z}+d \dot{z}+k z+F_{g} .
$$

The mechanical and electrical behavior of piezoelectric material is modeled through (2) [2]. Parameter $\Gamma$ is a measure for the coupling coefficient of the piezo element, and $C_{0}$ is the clamped capacitance of the piezo element. The stiffness of the piezo element is neglected in (2), and is assumed to be incorporated by the mechanical spring constant $k$.

$$
\left\{\begin{array}{c}
F_{g}=\Gamma V \\
I=\Gamma \dot{z}-C_{0} \dot{V}
\end{array}\right.
$$

Fig. 2 shows an electrical circuit equivalent of the harvester model, including the piezoelectric element. In this electric circuit, the voltages represent forces, and charges represent displacements. 


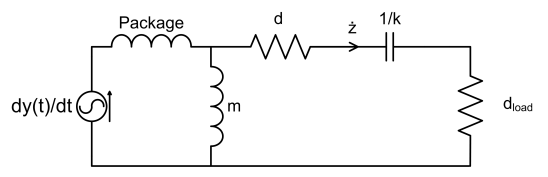

Fig. 3. Electronic equivalent of a velocity damped inertial energy harvester.

\section{OPTIMAL POWER OUTPUT}

\section{A. Power Output Limit}

In literature, much work has been done concerning the optimal power flow of the harvester in case the load is a linear resistor (see a.o. [3]). Since the vibration-based harvester provides a varying $\mathrm{AC}$ power and while electronic loads rather need a stable DC power supply, it is useful to analyze the harvester behavior, when connected to an AC-DC rectifier. The output power of both load cases is compared to the theoretical absolute maximum output power of an inertial energy harvester, i.e. the output power of a harvester with the damping force of the generator proportional to the velocity of the seismic mass. An electronic equivalent of this theoretical harvester is given in Fig. 3. The output power dissipated in the load damping $d_{\text {load }}$, reaches a maximum at the resonance frequency $\omega_{\text {res }}=\sqrt{k / m}$, when the load resistor equals the parasitic damping $d$. The maximal output power is given by following equation, with $a$ the imposed acceleration on the system:

$$
P_{l i m}=\frac{a^{2} m^{2}}{8 d}
$$

\section{B. Resistive Load}

The harvested power dissipated in a resistive load is analytically calculated using the equivalent circuit in Fig. 2. For every operating frequency, an optimal load resistance exists $R_{o p t}$, given by (4), with $\omega_{s c}=\sqrt{(k / m)}$ the short circuit resonance frequency, and $\omega_{o c}=\sqrt{\left(\Gamma^{2}+C_{0} k\right) / C_{0} m}$ the open circuit resonance frequency of the system [4].

$$
R_{o p t}=\frac{1}{\omega C_{0}} \frac{\sqrt{\left(\omega_{s c}^{2}-\omega^{2}\right)^{2}+\frac{\omega^{2} d^{2}}{m^{2}}}}{\sqrt{\left(\omega_{o c}^{2}-\omega^{2}\right)^{2}+\frac{\omega^{2} d^{2}}{m^{2}}}}
$$

The corresponding output power dissipated in the optimal load resistance is:

$$
P_{o p t}=\frac{\frac{\omega^{5} Y^{2} \Gamma^{2}}{4 C_{0}}}{\frac{\Gamma^{2} \omega d}{C_{0} m^{2}}+\sqrt{\left(\frac{\omega^{2} d^{2}}{m^{2}}+\left(\omega^{2}-\omega_{s c}^{2}\right)^{2}\right)\left(\frac{\omega^{2} d^{2}}{m^{2}}+\left(\omega^{2}-\omega_{o c}^{2}\right)^{2}\right)}}
$$

The optimal harvested power depends on the electromechanical coupling factor $\kappa=\sqrt{\Gamma^{2} /\left(\Gamma^{2}+C_{0} k\right)}$. Fig. 4 gives a plot of the harvested output power for a varying operating frequency and with varying coupling factor. At both open and short circuit resonance frequencies, the output power tends to $P_{\text {lim }}$, for larger coupling factors.

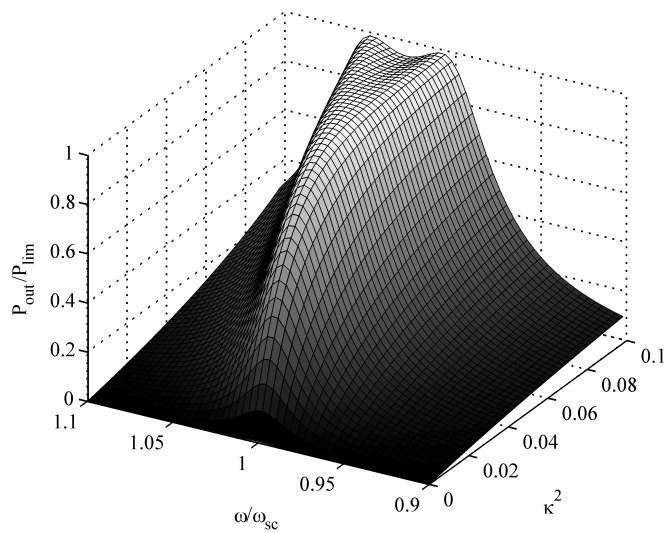

Fig. 4. Harvester power dissipated in the optimal resistive load versus operating frequency and squared coupling factor. $\left(m=1.1 e^{-3} \mathrm{~kg}, \mathrm{k}=\right.$ $\left.3970 \mathrm{~N} / \mathrm{m}, C_{0}=750 \mathrm{pF}, d=0.072 \mathrm{Ns} / \mathrm{m}, a=5 \mathrm{~m} / \mathrm{s}^{2}\right)$.

\section{AC-DC Rectifier Load}

The output power of an energy harvester connected to an AC-DC rectifier, with a fixed voltage $V_{c c}$ at the DC-side is analytically calculated as well. Analogous to the resistive loadcase, an optimal fixed output voltage exists for every operating frequency, and can be calculated from (6), with $a$ the (constant) acceleration of the mass, $z_{M}$ the amplitude of the displacement of the mass, and $\phi$ the phase difference between the applied force to the mass (i.e. the displacement of the package) and the displacement of the mass [4] [5].

$$
\left\{\begin{array}{l}
-\operatorname{macos}(\phi)=-m z_{M} \omega^{2}+k z_{M}+V_{c c} \Gamma \\
\operatorname{maz} z_{M} \sin (\phi) \frac{\pi}{2}=d z_{M}^{2} \omega \frac{\pi}{2}+2 V_{c c}\left(\Gamma z_{M}-V_{c c} C_{0}\right) \\
P_{\text {out }}=2 V_{c c} \frac{\omega}{\pi}\left(\Gamma z_{M}-V_{c c} C_{0}\right)
\end{array}\right.
$$

Similar to the resistive load-case, the optimal harvested power depends on the electromechanical coupling factor of the device. Fig. 5 gives a plot of the harvested output power at varying operating frequency and with varying coupling factor. For large coupling factors, the output power tends also to $P_{\text {lim }}$. There is no difference in maximal output power between both discussed load cases for a harvester device with large coupling coefficient. However, for weakly coupled harvester devices, a resistive load tends to capture more power out of the harvester device, as can be seen in Fig. 6.

\section{Harvester Example}

To illustrate the previous analysis, a piezo bimorph element is taken as energy harvesting device, with overall dimensions $15 \mathrm{~mm} \times 1.5 \mathrm{~mm} \times 0.6 \mathrm{~mm}(\mathrm{LxBxH})$, with a small mass attached to the tip. The open-circuit resonance frequency of the device lies around $301 \mathrm{~Hz}$. The measured model parameters of the device are given in Table I, the parameters are measured while imposing an acceleration of $5 \mathrm{~m} / \mathrm{s}^{2}$ to the harvesting device. Fig. 7 shows the output power of the bimorph device as predicted by the modeling above, together with the measured output power, for both resistive load and the load being an AC-DC rectifier with varying DC-voltage. The output power 
TABLE I

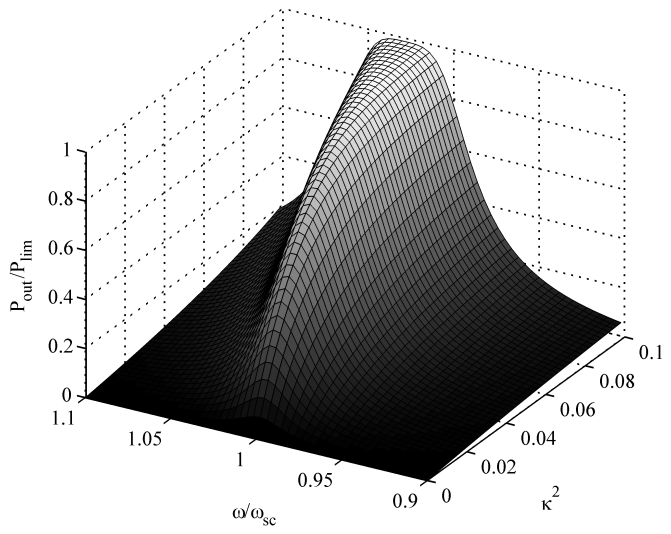

Fig. 5. Harvester power transferred to the optimal DC-load versus operating frequency and squared coupling factor. $(m=1.1 e-3 \mathrm{~kg}, \mathrm{k}=$ $\left.3970 \mathrm{~N} / \mathrm{m}, C_{0}=750 \mathrm{pF}, d=0.072 \mathrm{Ns} / \mathrm{m}, a=5 \mathrm{~m} / \mathrm{s}^{2}\right)$

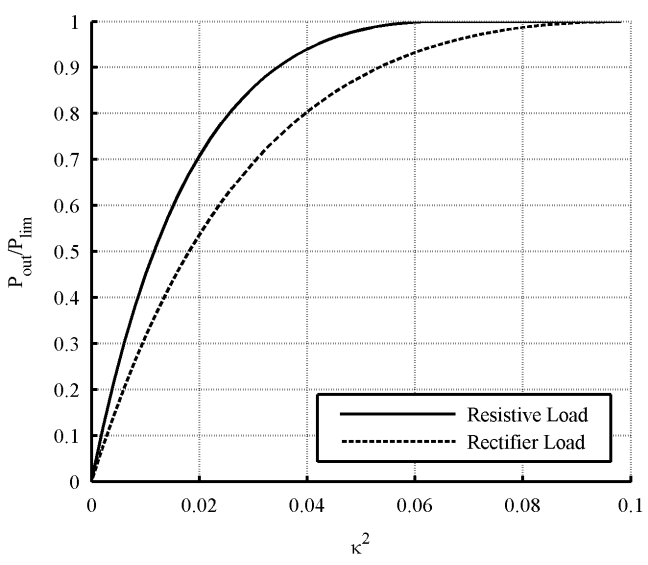

Fig. 6. Maximal harvester power for both load-cases versus squared coupling factor. $\left(m=1.1 e-3 \mathrm{~kg}, \mathrm{k}=3970 \mathrm{~N} / \mathrm{m}, C_{0}=750 \mathrm{pF}, d=\right.$ $\left.0.072 \mathrm{Ns} / \mathrm{m}, a=5 \mathrm{~m} / \mathrm{s}^{2}\right)$

is measured at the DC-side of the rectifier and does not incorporate the losses in the full-bridge diode rectifier, hence the difference between the modeled and measured power seen in fig. 7. The squared mechanical coupling factor $\kappa^{2}$ of the device is 0.03 , explaining the lower output power of the harvester with the rectifier load.

\section{Design of Power Processing Circuits}

As already stated, a power management circuit is needed to transform the scavenger output voltage to a DC voltage of an appropriate level, and moreover, the power management circuit should also provide the optimal load to the harvesting device. The choice can be made to provide the optimal resistive load to the harvester, but according to previous analysis, a fixed DC-voltage may allow the harvester to perform nearly optimal as well, depending on the electromechanical coupling factor of the harvester. The question is now how to decide when to
Measured Model Parameters of Bimorph Harvesting Device at AN INPUT ACCELERATION OF $5 \mathrm{~m} / \mathrm{s}^{2}$

\begin{tabular}{|c|c|c|c|}
\hline$m$ & $1.1 e^{-3} \mathrm{~kg}$ & $R_{\text {loadopt }}$ & $580 \mathrm{k} \Omega$ \\
\hline$d$ & $0.067 \mathrm{Ns} / \mathrm{m}$ & $P_{\text {Ropt }}$ & $49.4 \mu \mathrm{W}$ \\
\hline$k$ & $3970 \mathrm{~N} / \mathrm{m}$ & $V_{\text {ccopt }}$ & $6.1 \mathrm{~V}$ \\
\hline$\Gamma$ & $3 e^{-4} \mathrm{C} / \mathrm{m}$ & $P_{\text {Vopt }}$ & $39.8 \mu \mathrm{W}$ \\
\hline$C_{0}$ & $750 \mathrm{pF}$ & $f_{\text {opt }}$ & $301 \mathrm{~Hz}$ \\
\hline
\end{tabular}
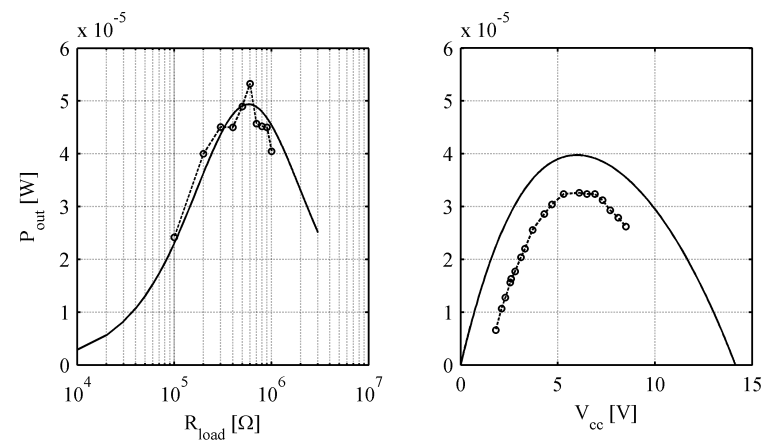

Fig. 7. Predicted and Measured Output power of Bimorph Device versus Resistive load (left), and AC-DC rectifier load (right).

use which power processing circuit. Therefore an efficiency analysis is made for both possible circuits.

\section{A. Processing Circuit Providing Resistive Load}

In [6] is shown that a buck-boost DC-DC converter without input filter capacitor, see Fig. 8, operating in discontinuous conduction mode, has a 'resistive' input impedance and may thus be well suited to operate as power processing circuit for harvesting devices. Fig. 9 shows the input current of the converter. The input resistance of the circuit $R_{i n}$ is controlled through the duty cycle of the switching element according to (7), with $L$ the used inductance, $f_{s}$ the switching frequency and $D$ the duty-cycle of the switching element. Note that (7) only holds if $f_{s} \gg f_{h}$, the input vibration frequency of the harvester. The output voltage $V_{\text {out }}$ of the converter is assumed to be held constant.

$$
R_{\text {in }}=\frac{2 L f_{s}}{D^{2}}
$$

For the efficiency analysis, the losses in the switch, the

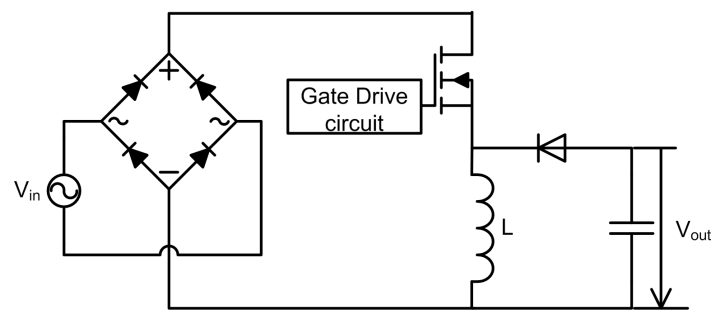

Fig. 8. Buck-boost converter without input filter capacitor. 


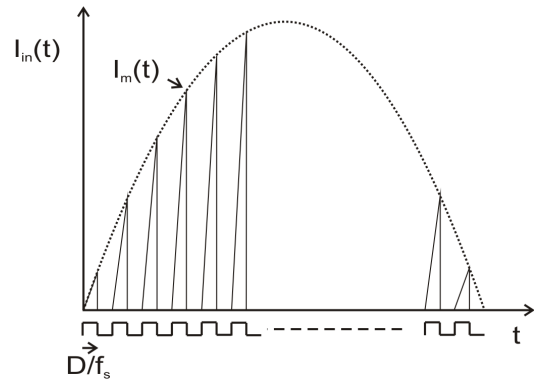

Fig. 9. Buck-boost converter without input filter capacitor.

diode, as well as the losses in the inductor due to its parasitic resistance, are taken into account.

1) Switch Loss: The MosFet loss $W_{m o s}$, is the sum of the conduction loss $P_{o n}$, the switching loss $W_{s w}$ and the gatedrive loss $P_{d r v}$ [7]. The conduction loss of the switch is given by (8), with $R_{o n}$ the on-resistance of the MosFet and $I_{m}(i)$ the peak input current during switching period $i$ and is calculated using (9). The input voltage of the converter $V_{i n}$ is assumed to be constant during a switching period.

$$
\begin{gathered}
P_{\text {on }}=f_{h} \sum_{i=1}^{f_{s} / f_{h}} \frac{R_{o n} I_{m}(i)^{2} D f_{s}}{3} \\
I_{m}(i)=\frac{V_{i n}(i) D}{L f_{s}}
\end{gathered}
$$

As the the converter operates in continuous conduction mode, the current is zero at the beginning of each switching period, so that the switching loss during on-switching of the MosFet is negligible. The total switching loss is given by :

$$
P_{s w}=f_{h} \sum_{i=1}^{f_{s} / f_{h}} \frac{1}{2}\left(V_{\text {in }}+V_{\text {out }}\right)(i) I_{m}(i) t_{\text {off }}+\frac{1}{2} V_{\text {in }}(i)^{2} C_{d s} .
$$

The second term in (10) refers to the drain-source capacitance loss. The gate-drive loss of the MosFet, is given by:

$$
P_{d r v}=V_{g s} Q_{g} f_{s}
$$

$V_{g s}$ and $Q_{g}$ are the gate-source voltage at the on-state and the gate charge.

2) Diode Loss: The diode loss is given by (12), with $V_{f}$ the diode forward voltage, and $t_{\text {diode }}$ the conduction time of the diode, given by (13).

$$
\begin{gathered}
P_{\text {diode }}=f_{h} \sum_{i=1}^{f_{s} / f_{h}} \frac{1}{2} V_{f} I_{m}(i) t_{\text {diode }}(i) \\
t_{\text {diode }}(i)=\frac{L I_{m}(i)}{V_{\text {out }}}
\end{gathered}
$$

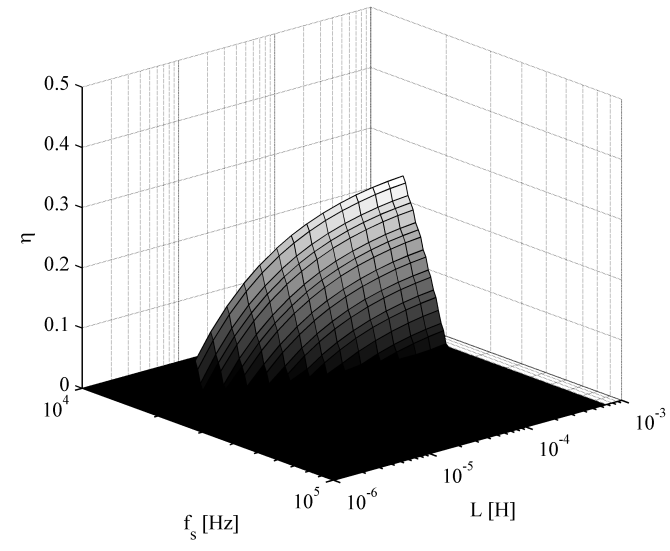

Fig. 10. Efficiency of buck-boost converter with a resistive input impedance of $580 \mathrm{k} \Omega$ and input power of $49.4 \mu \mathrm{W}$.

TABLE II

PARAMETERS OF DEVICES USED IN POWER PROCESSING CIRCUITS

\begin{tabular}{|c|c||c|c|}
\hline$R_{o n}$ & $2 \Omega$ & $Q_{g}$ & $0.3 \mathrm{nC}$ \\
\hline$t_{\text {off }}$ & $5 \mathrm{~ns}$ & $V_{f}$ & $0.6 \mathrm{~V}$ \\
\hline$C_{d s}$ & $5 \mathrm{pF}$ & $R_{e s r}$ & $45 \mathrm{k} \Omega / \mathrm{H}$ \\
\hline$V_{g s}$ & $5 \mathrm{~V}$ & & \\
\hline
\end{tabular}

3) Inductor Loss: The loss in the inductor $W_{\text {ind }}$ due to its series resistance $R_{e s r}$ is given by:

$$
P_{\text {ind }}=f_{h} \sum_{i=1}^{f_{s} / f_{h}} R_{e s r} I_{m}^{2}(i)\left(\frac{\frac{D}{f_{s}}+t_{\text {diode }}}{3}\right) .
$$

The efficiency of the converter is then expressed as :

$$
\eta=\frac{P_{i n}}{P_{\text {in }}+P_{\text {on }}+P_{s w}+P_{d r v}+P_{\text {diode }}+P_{\text {ind }}} .
$$

The efficiency of a converter to be used as power processing circuit for the previously mentioned bimorph harvester device, is calculated for varying switching frequency and inductance. The optimal resistive load conditions of the bimorph harvesting device (see Table I), are taken as input for the efficiency calculations. The device parameters used are listed in Table II. An output voltage of is $3 \mathrm{~V}$ chosen. An extra constraint is given by the fact that the harvester output voltage is not allowed to drop too much during the switch on-time. At lower switching frequencies, the on-time of the harvester increases according to (7), as well as the peak-current during each switching period, see (9). The voltage on the output capacitor of the harvester will drop substantially during the on-time of the switch in these operating conditions, inhibiting proper operation of the converter, therefore the efficiency is set to zero in these conditions. Fig. 10 shows a surface plot of the calculated efficiency versus switching frequency and inductance. The highest efficiency, $25.7 \%$, is reached using a switching frequency of $15.5 \mathrm{kHz}$ and an inductance of $680 \mu \mathrm{H}$. The duty cycle in this point is $0.6 \%$ 


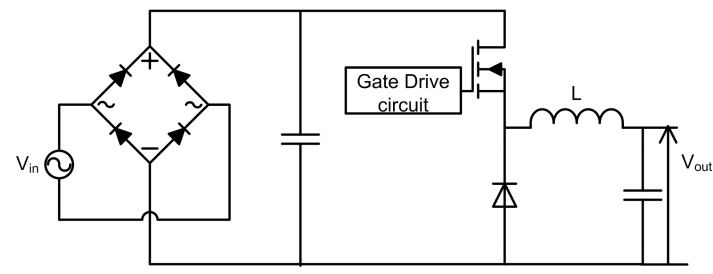

Fig. 11. Buck converter with input filter capacitor.

\section{B. Processing Circuit Providing Fixed Voltage}

A fixed DC-voltage can be provided through e.g. a buck converter with a sufficiently large input filter capacitor, see Fig. 11. The input voltage of the converter is controlled through the duty-cycle. Because of the very low power processed by the circuit, the converter is most likely to operate in discontinuous conduction mode. The duty cycle of a buck converter in discontinuous conduction mode is calculated as follows [8]:

$$
D=\frac{V_{\text {out }}}{V_{\text {in }}} \sqrt{\frac{I_{\text {out }}}{I_{L B \max }\left(1-V_{\text {out }} / V_{\text {in }}\right)}} .
$$

$I_{L B \max }$ is the average inductor current at the boundary between continuous and discontinuous conduction mode, and is given by:

$$
I_{L B \max }=\frac{V_{\text {out }}}{2 L f_{s}} .
$$

The peak current through the inductor is :

$$
I_{\text {peak }}=\frac{\left(V_{\text {in }}-V_{\text {out }}\right) D}{L f_{s}} .
$$

1) Switch Loss: The MosFet conduction loss can be obtained as

$$
P_{\text {on }}=\frac{R_{\text {on }} I_{\text {peak }}^{2} D}{3}
$$

The switching loss is

$$
P_{s w}=\frac{1}{2} V_{i n} I_{\text {peak }} t_{o f f} f_{s}+V_{i n}^{2} C_{d s} f_{s} .
$$

As only discontinuous conduction is considered, no switching loss occurs during on-switching of the MosFet. The gate drive loss is given by (11).

2) Diode Loss: The diode loss can be obtained as :

$$
P_{\text {diode }}=\frac{1}{2} V_{f} I_{\text {peak }} t_{\text {diode }} f_{s}
$$

with

$$
t_{\text {diode }}=\frac{D\left(V_{\text {in }} / V_{\text {out }}-1\right)}{f_{s}} .
$$

3) Inductor Loss: The inductance loss due to its series resistance can be calculated with

$$
P_{\text {ind }}=R_{\text {esr }} I_{\text {peak }}^{2} f_{s} \frac{D / f_{s}+t_{\text {diode }}}{3} .
$$

The efficiency of a buck converter is calculated for varying switching frequency and inductance, using the optimal DCload conditions of the bimorph harvesting device as input (see Table I). An output voltage of is $3 V$ chosen. Fig. 12 shows

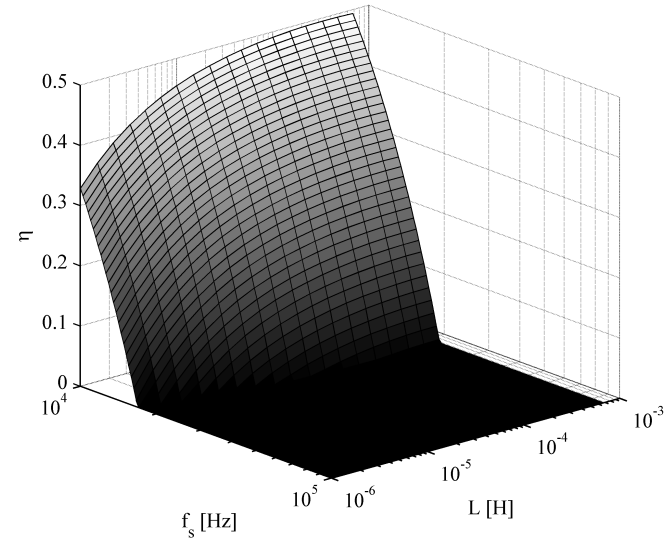

Fig. 12. Efficiency of buck converter with an input voltage of $4.9 \mathrm{~V}$ and input power of $39.8 \mu \mathrm{W}$,

a surface plot of the calculated efficiency versus switching frequency and inductance. The highest efficiency, $49.5 \%$, is reached using a switching frequency of $10 \mathrm{kHz}$ and an inductance of $330 \mu \mathrm{H}$. The duty cycle in the optimal point is $0.53 \%$.

From Fig. 10 and 12, it can be concluded that the optimal efficiency of a buck converter with fixed input voltage is considerably higher than the efficiency of a buck-boost converter emulating resistive input impedance. It must be noted that the theoretical optimal efficiencies are rather low, because of the very low given power budget. The overall efficiency of the harvesting system including the power processing circuit will be higher for the buck converter with fixed input voltage, for the piezo bimorph harvester example. Note that in the efficiency calculations, the losses in the rectifier circuit are left out of consideration.

\section{Simulations}

Both power management circuits have been implemented in PSpice, and have been simulated together with the electronic circuit equivalent of the bimorph piezo energy harvester. The used MosFet-model is a 2N7002 [9], and the diode-model is a BAS16W [10]. The energy harvester is driven at its shortcircuit resonance frequency. The switching frequency and the inductance value of both power management circuits are taken from the optimal efficiency point in previous calculations. A comparison of the simulation results with the theoretical calculations is given in Table III, Circuit1 represents the buckboost converter emulating resistive load, Circuit2 is the buckconverter providing a fixed input voltage to the harvester. The simulated efficiencies are higher than the previously calculated ones, mainly because the diode and gate drive losses are conservatively overestimated in the calculations. The simulated diode losses are lower because in the calculations is assumed that the diode starts to conduct immediately after the MosFet is switched off. In reality, the time to forward bias the diode can not be neglected because the inductor current, biasing the diode, is very low, and $t_{\text {diode }}$ is very small. The gate drive losses of the MosFet are much lower in simulations because 
TABLE III

COMPARISON OF PSPICE SIMULATION RESULTS AND THEORETICAL EFFICIENCY CALCULATIONS

\begin{tabular}{|c||l|l|l|l|}
\hline & $\begin{array}{l}\text { Circuit1 } \\
\text { PSpice }\end{array}$ & $\begin{array}{l}\text { Circuit1 } \\
\text { Analytical }\end{array}$ & $\begin{array}{l}\text { Circuit2 } \\
\text { PSpice }\end{array}$ & $\begin{array}{l}\text { Circuit2 } \\
\text { Analytical }\end{array}$ \\
\hline$P_{\text {harvester }}$ & $41 \mu W$ & $49.4 \mu W$ & $32 \mu W$ & $39.8 \mu W$ \\
\hline$P_{\text {out }}$ & $11.5 \mu W$ & $12.7 \mu W$ & $15.9 \mu W$ & $19.7 \mu W$ \\
\hline$P_{\text {rectifier }}$ & $11.2 \mu W$ & NA & $6.5 \mu W$ & NA \\
\hline$P_{\text {diode }}$ & $3.5 \mu W$ & $9.8 \mu W$ & $0.8 \mu W$ & $3 \mu W$ \\
\hline$P_{\text {mos }}$ & $14.2 \mu W$ & $26.2 \mu W$ & $4.4 \mu W$ & $16.6 \mu W$ \\
\hline$P_{\text {drv }}$ & $4.5 \mu W$ & $23 \mu W$ & $3.2 \mu W$ & $15 \mu W$ \\
\hline$P_{\text {ind }}$ & $0.8 \mu W$ & $0.6 \mu W$ & $0.4 \mu W$ & $0.4 \mu W$ \\
\hline$\eta$ & $28.1 \%$ & $25.7 \%$ & $49.7 \%$ & $49.5 \%$ \\
\hline
\end{tabular}

the gate charge $Q_{g}$ is lower than given in the datasheet of the MosFet, due to the very low drain-source currents.

\section{EXPERIMENTAL RESULTS}

Both DC-DC converters have been built on a printed circuit board using commercially available discrete devices. The used MosFet is a 2N7002, the diode is a BAS16W. The inductors are ferrite drum core inductors in a SMD 1210-package. The buck-boost converter used to impose the resistive load to the harvester (Circuit1) has an inductor of $680 \mu \mathrm{H}$, the inductor in the buck converter (Circuit2) has an inductance of $330 \mu \mathrm{H}$. A PIC18F4550 microcontroller is used to generate the PWM gate-drive signals, and IR2302 is the gate-driver. The turn-on rise time and the turn-off fall time and the propagation delays of the gate driver restrict the on-time gate signal of MosFet to be at least $800 \mathrm{~ns}$. This means that the use of the switching frequencies of the previously calculated optimal efficiency points is not possible. Circuit1 is chosen to be driven with a switching frequency of $12 \mathrm{kHz}$, for Circuit2 a switching frequency of $3 \mathrm{kHz}$ is used. The output voltage on both circuits is set to $1 \mathrm{~V}$, and the piezo bimorph harvester is driven at its short circuit resonance frequency with an acceleration of $5 \mathrm{~m} / \mathrm{s}^{2}$. A summary of the main measurements on both circuits is given in Table IV.

The emulated input resistance of Circuit1 is, according to (7), about $177 \mathrm{k} \Omega$. The output power of the harvester is measured to be about $40 \mu \mathrm{W}$, this value is consistent with the theoretical output of the harvester as seen in Fig. 7. From this measurement can be concluded that the input resistance emulated by the buck-boost converter is correctly seen by the energy harvester. The efficiency of the converter though is very low, as no output power could be measured.

Using Circuit2, the voltage at the output of the harvester, after rectification, is set to $2.6 \mathrm{~V}$, the measured output voltage is about $32 \mu W$, and this value is also quite consistent with the theoretical value as shown in Fig. 7. The efficiency of the converter is about $10 \%$, without taking the power loss in the gate driver into account.

From the measurements can be concluded that the overall efficiency of the harvesting system with power processing circuit will be higher if a standard buck-converter circuit
TABLE IV

MEASUREMENTS ON BOTH POWER PROCESSING CIRCUITS

\begin{tabular}{|c||c|c|}
\hline & Circuit1 & Circuit2 \\
\hline$f_{s}$ & $12 \mathrm{kHz}$ & $3 \mathrm{kHz}$ \\
\hline Duty Cycle & $0.96 \%$ & $0.3 \%$ \\
\hline$P_{\text {harvester }}$ & $40.5 \mu \mathrm{W}$ & $32 \mu \mathrm{W}$ \\
\hline$P_{\text {out }}$ & $0 \mu \mathrm{W}$ & $3.3 \mu \mathrm{W}$ \\
\hline
\end{tabular}

is used, as was predicted by theoretical calculations and simulations.

\section{CONCLUSION}

In this paper the behavior of a piezo-electric vibrationdriven energy harvester is assessed with two different power processing circuits. A general model for vibration-driven harvesters is described. Using this model, both an optimal linear resistive load, as an optimal DC voltage load, for the harvester can be analytically calculated for every frequency. The optimal output power of the harvester connected to both different loads depends on the coupling coefficient of the device. To determine which load leads to the optimal overall efficiency of a system consisting of an energy harvester connected to a power processing circuit, two power processing circuits are designed: the first one emulating a resistive input impedance and the second one with a constant input voltage. A buck-boost DC-DC converter without input filter capacitor, operating in discontinuous conduction mode, is shown to have a resistive input impedance. A buck converter with input filter capacitor is used to evaluate the rectifier load case. An analytic loss model of both converters is set up to determine the optimal operating point of the converter. The calculations show that the efficiency of the converter emulating a resistive input impedance is much lower than the buck converter with a fixed input voltage. Hence, it can be concluded that the efficiency of the overall system of a harvesting device with power processing circuit will be better if the processing circuit has a fixed DC-voltage as input. This conclusion is validated through simulations and experimental measurements.

\section{ACKNOWLEDGMENT}

Research presented in this paper is supported by the IWT (Institute for Promotion and Innovation by Science and Technology in Flanders) under the project SBO 030288 PowerMEMS.

\section{REFERENCES}

[1] S. Roundy, P. Wright, and J. Rabaey, "A study of low level vibrations as a power source for wireless sensor nodes," Computer Communications, vol. 26, no. 11, pp. 1131-1144, July 2003.

[2] T. Sterken, K. Baert, C. Van Hoof, R. Puers, G. Borghs, and P. Fiorini, "Comparative modelling for vibration scavengers [MEMS energy scavengers]," in Sensors, 2004. Proceedings of IEEE, Oct. 2004, pp. 1249-1252.

[3] P. Mitcheson, T. Green, E. Yeatman, and A. Holmes, "Architectures for vibration-driven micropower generators," Journal of Microelectromechanical Systems, vol. 13, no. 3, pp. 429-440, 2004. 
[4] R. D'hulst, T. Sterken, P. Fiorini, R. Puers, and J. Driesen, "Energy scavengers : Modeling and behavior with different load circuits," in Industrial Electronics Society, 2007. IECON 2007. 33rd Annual Conference of the IEEE, Taipei, Taiwan, Nov. 2007, pp. 2169-2174.

[5] Y. Shu and I. Lien, "Analysis of power output for piezoelectric energy harvesting systems," Smart Materials and Structures, vol. 15, no. 6, pp. 1499-1512, Dec. 2006.

[6] R. D'hulst, P. Mitcheson, and J. Driesen, "Cmos buck-boost power processing circuitry for powermems harvesters," in $6^{\text {th }}$ International Workshop on Micro \& Nanotechnology for Power Generation and Energy Conversion Applications (PowerMEMS), Berkeley USA, Nov. 29th - Dec. 1st, 2006.
[7] R. Sodhi, S. Brown, S., and D. Kinzer, "Integrated design environment for DC/DC converter FET optimization," in Power Semiconductor De vices and ICs, 1999. ISPSD '99. Proceedings., The 11th International Symposium on, Toronto, Ont., May 1999, pp. 241-244.

[8] N. Mohan, T. M. Undeland, and W. P. Robbins, Power Electronics Converters, Application and Design. John Wiley \& Sons, 2003.

[9] 2N7002, N-channel enhancement mode field effect transistor, Fairchild Semiconductor, Nov. 1995

[10] BAS16W, High speed diode, NXP Semiconductors, May 1999. 